\title{
Potential effects of intrinsic heart pacemaker cell mechanisms on dysrhythmic cardiac action potential firing
}

\author{
Yael Yaniv ${ }^{1 *}$, Kenta Tsutsui ${ }^{2}$ and Edward G. Lakatta ${ }^{2 *}$ \\ Biomedical Engineering Faculty, Technion-Israel Institute of Technology, Haifa, Israel \\ ${ }^{2}$ Laboratory of Cardiovascular Science, Biomedical Research Center, Intramural Research Program, National Institute on Aging, National Institutes of Health, \\ Baltimore, MD, USA
}

\section{Edited by:}

George E. Billman, The Ohio State

University, USA

Reviewed by:

Vadim V. Fedorov, The Ohio State

University, USA

Thomas Hund, The Ohio State

University, USA

\section{*Correspondence:}

Yael Yaniv, Biomedical Engineering Faculty, Technion-Israel Institute of Technology, 3200003 Haifa, Israel e-mail:yaely@bm.technion.ac.il;

Edward G. Lakatta, Laboratory of Cardiovascular Science, Biomedical Research Center, Intramural Research Program, National Institute on Aging, NIH, 251 Bayview Blvd, Baltimore, 21224 MD, USA

e-mail: lakattae@grc.nia.nih.gov
The heart's regular electrical activity is initiated by specialized cardiac pacemaker cells residing in the sinoatrial node. The rate and rhythm of spontaneous action potential firing of sinoatrial node cells are regulated by stochastic mechanisms that determine the level of coupling of chemical to electrical clocks within cardiac pacemaker cells. This coupled-clock system is modulated by autonomic signaling from the brain via neurotransmitter release from the vagus and sympathetic nerves. Abnormalities in brain-heart clock connections or in any molecular clock activity within pacemaker cells lead to abnormalities in the beating rate and rhythm of the pacemaker tissue that initiates the cardiac impulse. Dysfunction of pacemaker tissue can lead to tachy-brady heart rate alternation or exit block that leads to long atrial pauses and increases susceptibility to other cardiac arrhythmia. Here we review evidence for the idea that disturbances in the intrinsic components of pacemaker cells may be implemented in arrhythmia induction in the heart.

Keywords: arrhythmias, atrial fibrillation, coupled-clock pacemaker system, heart rate variability, sinus node disease

\section{INTRODUCTION}

Normal cardiac impulse initiation and conduction are generated by specialized, self-excitable, pacemaker cells residing in the sinoatrial node (SAN). Defects in these cell-intrinsic capacities to elicit spontaneous action potentials (APs) can lead to disturbances of the rate and rhythm of heart beats, and can induce numerous clinical arrhythmia syndromes: (i) SAN dysfunction has been postulated to be a source of sinus nodal re-entry (i.e., reciprocal beats between SAN and atrium) tachyarrhythmia (Birchfield et al., 1957) which accounts for $2-17 \%$ of all arrhythmias (Cossu and Steinberg, 1998). While diagnosis of this arrhythmia is difficult, due to electrocardiographic similarity of the P-wave to the normal sinus rhythm (Gomes et al., 1995), microelectrode studies in isolated rabbit hearts (Han et al., 1968) and later in humans (Childers et al., 1973) indeed demonstrate that SAN is the source that induces re-entry. (ii) Sick sinus syndrome, characterized by symptomatic dysfunction of the SAN (reviewed in Dobrzynski et al., 2007), can be manifested as sinus bradycardia, sinus arrest, or SAN block, and in some cases supraventricular tachyarrhythmias ("tachy-brady" syndrome), atrial flutter or atrial fibrillation. In mice with an inducible phenotype that mimics sick sinus syndrome, heart beating intervals (BIs) were completely irregular both in vivo and in the isolated Langendroff perfused model (no brain-heart signaling) (Herrmann et al., 2007). Telemetric ECG recordings revealed a variety of arrhythmias: sino-atrial arrhythmia, sino-atrial pause and supraventricular or ventricular tachycardia. (iii) It has been suggested that abnormal stretch of the rat atria that accompanies many heart diseases (De Jong et al., 2013) and occurs even in transplanted human hearts (Slovut et al., 1998) (no brain-heart connection) induces respiratory sinus arrhythmia.

Here we review evidence for the idea that changes in the membrane and sarcoplasmic reticulum (SR) components of pacemaker cells may be implicated in arrhythmia induction in the heart.

\section{INTRINSIC COUPLED-CLOCK MECHANISMS TO PACEMAKER CELLS CONTROL THE HEART RATE AND RHYTHM}

To understand abnormal SAN function it is essential to first understand the normal function of intrinsic properties of pacemaker cells and their modulation by brain-heart signaling. Experimental and theoretical data over the past two decades indicate that pacemaker cells residing in the SAN entrain their AP BI variability (BIV) by regulation of intracellular electric and mechanical coupling (reviewed in Yaniv et al., 2013a).

The coupled-clock system (Yaniv et al., 2013b; Maltsev et al., 2014) that controls the pacemaker cell beating rate and rhythm consists of an intracellular " $\mathrm{Ca}^{2+}$ clock" and "M clock." The sarcoplasmic reticulum $\mathrm{Ca}^{2+}$ pump and ryanodine channels act as a " $\mathrm{Ca}^{2+}$ clock," discharging local $\mathrm{Ca}^{2+}$ releases (LCRs) close to the cell surface membrane; LCRs activate membrane electrogenic clock molecules ("M clock"), mainly the $\mathrm{Na}^{+} / \mathrm{Ca}^{2+}$ exchanger. $\mathrm{Na}^{+}-\mathrm{Ca}^{2+}$ exchange current, the f-channel current, and $\mathrm{K}^{+}$channel current, other components of the $\mathrm{M}$ clock, concurrently drive the diastolic membrane depolarization to ignite the next AP. The $\mathrm{Ca}^{2+}$ and M clocks entrain each 
other through electrical and chemical signaling: $\mathrm{Ca}^{2+}$ activation of calmodulin -adenylyl cyclase (AC)-dependent protein kinase A (PKA) and $\mathrm{Ca}^{2+} /$ calmodulin-dependent protein kinase II (CaMKII). Both of these signaling pathways affect phosphorylation of proteins of both clocks [i.e., phospholamban (PLB) and ryanodine receptors $\left(\mathrm{Ca}^{2+}\right.$ clock) and $\mathrm{L}$ type and $\mathrm{K}^{+}$channels $(\mathrm{M}$ clock)]. Additionally, cAMP positively shifts the f-channel activation curve. Based on the coupled-clock theory, a change in the activity or in the quantity of every molecule within the $M$ or the $\mathrm{Ca}^{2+}$ clock or a change in the chemical coupling signaling of both clocks will perturb the function of the other clock, and thus alter the degree of entrainment between them. For example, in rabbit pacemaker cells, reduction in $\mathrm{I}_{f}$ activity or in $\mathrm{Ca}^{2+}$ clock proteins leads to reduction in the coupled-clock phosphorylation activity and LCR signal (Yaniv et al., 2014b). Thus, a reduction of internal signaling within one clock can lead to a reduction in the degree of clock coupling and changes in the function of the other clock that change automaticity.

Even under normal conditions, spontaneous AP BIs of mammals including human pacemaker cells are not constant, but vary around the average AP BI, due to stochastic properties of intrinsic mechanisms of the coupled-clock system (Verheijck et al., 1998; Rocchetti et al., 2000; Zaza and Lombardi, 2001; Monfredi et al., 2013; Papaioannou et al., 2013; Yaniv et al., $2014 b)$. The degree of AP BIV is related to variability in both the timing of LCR occurrence during the diastolic depolarization, and to the ensemble LCR $\mathrm{Ca}^{2+}$ signal: an increase in LCR variability is associated with a reduced ensemble LCR $\mathrm{Ca}^{2+}$ signal that occurs later in diastole (i.e., prolonging the next AP ignition). Based on the coupled-clock theory, the stochasticity of LCR periods (i.e., the times of LCR occurrences following the prior AP) not only depends upon stochasticity of spontaneous RyR activation, but also upon stochastic sarcolemmal ion channel openings and closings that regulate the cell $\mathrm{Ca}^{2+}$ balance. The amplitude and timing of LCR $\mathrm{Ca}^{2+}$ signals to $\mathrm{M}$ clock proteins report the efficiency of clock coupling, i.e., a weaker LCR signal to $M$ clock proteins that occurs later in time reports less-efficient clock coupling. Consequently, changes in the steady-state AP BI and the BIV embody contributions of both clocks. Reduction in the degree of synchronization between the clocks disturbs the ability to maintain the basal average $\mathrm{AP} \mathrm{BI}$, leading not only to a reduction in the average AP BI, but also to an increase in variability around the prolonged average AP BI.

Autonomic neural input can entrain the rate and rhythm of electrical impulses that are generated by SAN tissue of mammals (Difrancesco, 1993; Boyett et al., 2000; Monfredi et al., 2014; Yaniv et al., 2014a). The balance between sympathetic to parasympathetic stimulation has a role in synchronizing intrinsic clock periods of individual pacemaker cells. $\beta$ adrenergic receptor stimulation increases synchronization of intrinsic clock mechanisms leading to a decrease of both BI and BIV of pacemaker cells (Figures 1B,C). Moreover, $\beta$ adrenergic receptor stimulation of a single pacemaker cell increases the probability that the beating intervals exhibit fractal-like behavior. Cholinergic receptor stimulation of pacemaker cells, on the other hand, decreases synchronization of intrinsic clock mechanisms, leading to an increase of both the average BI and BIV (Figures 1B,C).

\section{SYNCHRONIZATION OF ACTIVITY ACROSS THE POPULATION OF CELLS CAN IMPACT ON THE HEART RATE AND RHYTHM}

Although we have focused here upon synchronization of mechanisms intrinsic to pacemaker cells, cell-to-cell interactions (electrotonic and mechanical) of pacemaker cells residing in SAN tissue also entrain the rate and rhythm of electrical impulses that emanate from the SAN (Jalife, 1984; Watanabe et al., 1995). These interactions have a role in synchronizing the intrinsic clock periods of individual cells (Sheikh et al., 2013), because the average range of basal AP BI and AP BIV of single isolated pacemaker cells is well above their range when they reside in rabbit SAN tissue (Yaniv et al., 2014a) (Figure 1A). When pacemaker cells are embedded within SAN tissue, those with the shortest AP BI create a primary pacemaker area within the SAN, leading to the origin of an electrotonic force that spreads to other SAN cells, resulting in the emanation of an electric impulse that excites the rest of the heart (Anumonwo et al., 1991). This impulse controls the heart rate and rhythm. When rabbit pacemaker cells are isolated from SAN tissue, their beating interval entropy increases dramatically compared to that when these cells reside in SAN tissue (Figure 1B), and fractal-like behavior of AP BIs, a feature that characterizes AP BI of SAN tissue, is absent in isolated single pacemaker cells (Yaniv et al., 2014a).

\section{CHANGES IN HEART RATE VARIABILITY INDEXES AND THE PRESENCE OF ARRHYTHMIA}

An increase in pacemaker cells AP BIV, or in mathematical terms coupled-clock-system entropy, above a certain threshold leads to abnormal impulse generation by the SAN that is defined as arrhythmia. Two regimes of heart rate variability (HRV) are analyzed in patients with arrhythmogenic events: during the events when the entropy of the system increases (Costa et al., 2008), and before the occurrence of arrhythmia. The occurrence of major arrhythmic events in patients with right ventricular cardiomyopathy is associated with a reduced BIV (Battipaglia et al., 2012). Interestingly, heart rate variability indexes decrease just prior to an arrhythmogenic event (Postolache et al., 2011). As we summarized here, the degree of synchronization of intrinsic mechanisms to pacemaker cells and the degree of synchronization among pacemaker cells within the SAN are determinants of the heart rate and rhythm. Autonomic receptors on pacemaker cells respond to the imbalances of autonomic impulses associated with cardiac diseases. Specifically, autonomic receptor stimulation of single pacemaker cells alters their beat-to-beat variability. Thus, intrinsic pacemaker mechanisms may contribute to HRV in vivo. Although mechanisms of HRV may vary from one patient to another, documentation of the relationship between HRV and different arrhythmias in human patients (Table 1) is an important initial step to conceptually link intrinsic pacemaker mechanisms to arrhythmogenic events. Note, that this sort of evidence, however, does not prove that altered synchronization of pacemaker clock mechanisms residing within the SAN are the sole cause of all patient arrhythmias that may be linked to changes in HRV. 


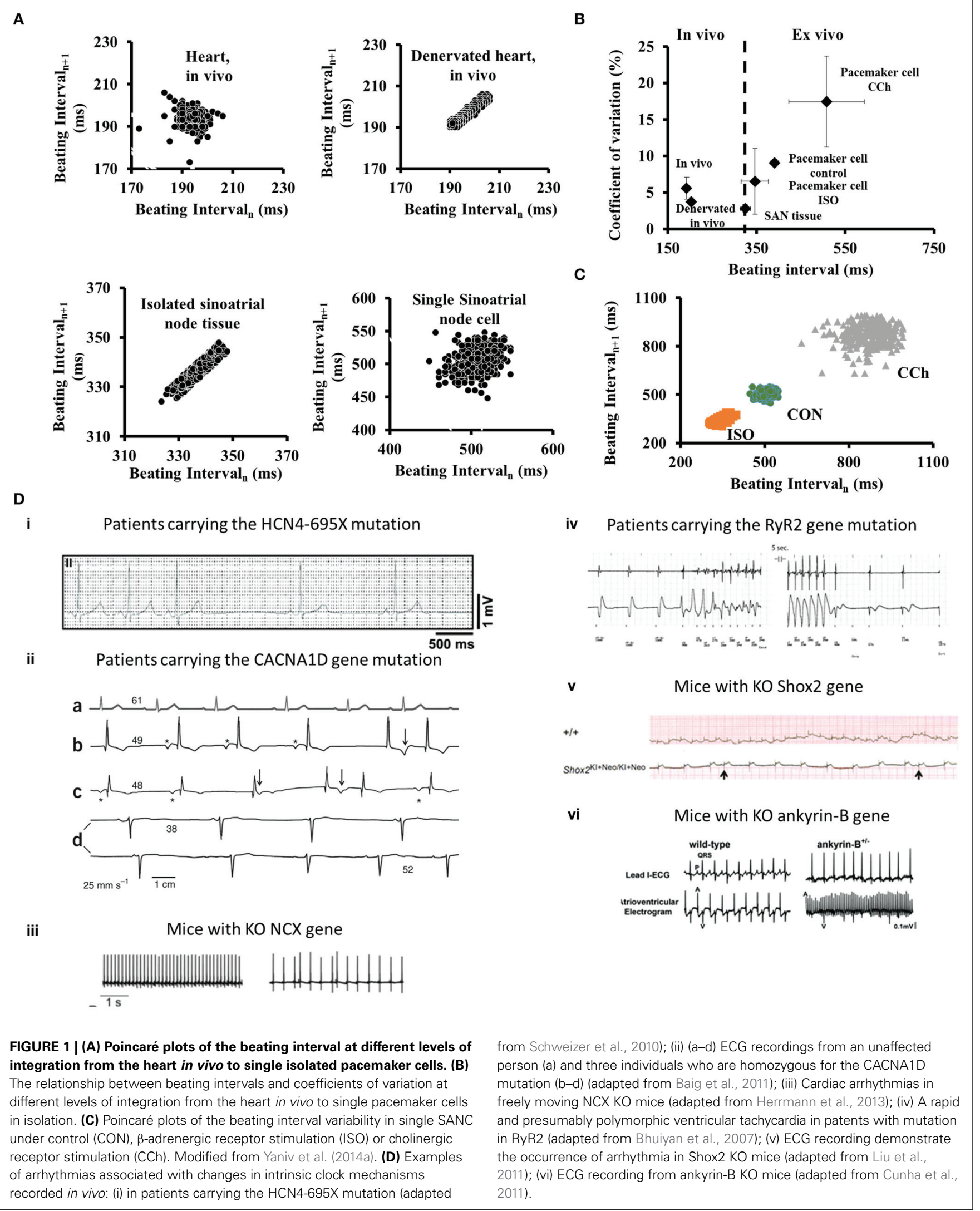


Table 1 | Summary of primary studies assessing the changes of heart rate variability when arrhythmia occurs.

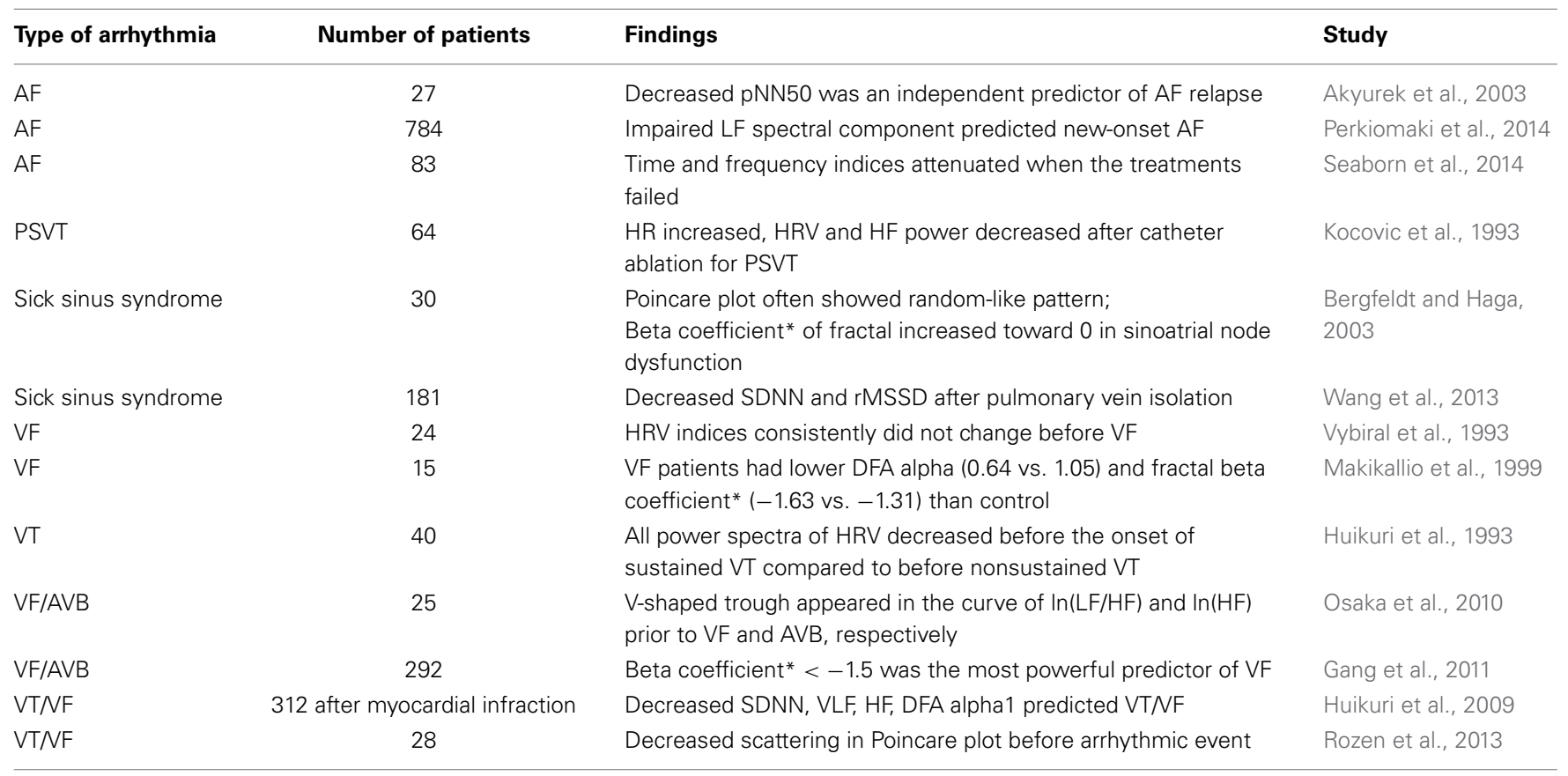

PSVT, Paroxysmal supraventricular tachycardia; VF, Ventricular fibrillation; VT, Ventricular tachycardia; AF, atrial fibrillation; AVB, atrioventricular block; DFA, Detrended fluctuation analysis; pNN50, the number of pairs of successive beats that differ by more than $50 \mathrm{~ms}$; SDNN, standard deviation of the average beating intervals;

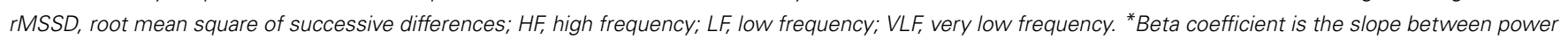
spectra and VLF in log-log scale.

\section{DIRECT PHARMACOLOGICAL INHIBITION OF COUPLED-CLOCK PROTEINS OF PACEMAKER CELLS CAUSES CHANGES IN RATE AND RHYTHM}

Direct pharmacological inhibition of coupled-clock proteins can induce arrhythmias. For example: (i) caging of intracellular $\mathrm{Ca}^{2+}$ by NP-EGTA in isolated rabbit pacemaker cells induces an increase in LCR variability and AP BI bradycardia together with arrhythmic events (Yaniv et al., 2011). (ii) A sudden increase in stochastic ryanodine receptor open probability, elicited by caffeine spritz in isolated rabbit pacemaker cells, induces tachycardia, together with arrhythmic events (Yaniv et al., 2013d). (iii) Specific PKA inhibitors (Younes et al., 2008) or CaMKII inhibitors (Yaniv et al., 2013c) superfused onto isolated rabbit pacemaker cells induce AP BI bradycardia together with arrhythmic events. (iv) Perturbing clock coupling in rabbit pacemaker cells by directly inhibiting either the $\mathrm{M}$ (ivabradine, an $\mathrm{I}_{f}$ inhibitor) or $\mathrm{Ca}^{2+}$ clock (cyclopiazonic acid, a SR $\mathrm{Ca}^{2+}$ pump inhibitor) produces increases in AP BI and AP BIV that are related to increases in LCR period and LCR period variability (Yaniv et al., 2014b). These results provide evidence that supports the coupled-clock theory, demonstrating the ability of the LCR $\mathrm{Ca}^{2+}$ signal to report the degree of synchronization between the two clocks, and how changes in the degree of synchronization lead to changes in AP BI and AP BIV.

\section{REDUCED EFFICIENCY OF INTRINSIC COUPLED-CLOCK PACEMAKER MECHANISMS AND ARRHYTHMIA}

Similar to direct pharmacological inhibitors of coupled-clock proteins, mutation and genetically induced gene deletion of different components of the coupled-clock system are associated with arrhythmias in vivo.

\section{HCN GENE}

The hyperpolarization-activated channel $\left(I_{f}\right)$ consists of three HCN members (HCN1, HCN2, and HCN4) (Ludwig et al., 1998). HCN4 comprises the major fraction $(70-80 \%)$ of SAN $I_{\mathrm{f}}$. Various mutations of human HCN4 channels are associated with arrhythmias, and with bradycardia in particular (Yeh et al., 2009; Schweizer et al., 2010; Duhme et al., 2013). Interestingly, the spontaneous cardiac beating rate of HCN4knockout embryos is significantly slower than that of wildtype, but no arrhythmic events are observed. These results are in contrast to the conditional deletion of HCN4 in adult animals, where bradycardia is not evident but sinus pauses are detected (Stieber et al., 2004; Herrmann et al., 2007; Yeh et al., 2009) (Figure 1D). Other HCN transcripts that compose funny current channel in the mouse are $\mathrm{HCN} 2$, and a low level of HCN1. HCN2-deficient mice display mild cardiac dysrhythmia, both in the presence and absence of autonomic control of the heart rate (Stieber et al., 2004; Herrmann et al., 2007). Similarly, HCN1-deficient mice exhibit sinus dysrhythmia in vivo and in single isolated cells (Fenske et al., 2013). Interestingly, HCN1-deficient mice exhibit high beat-tobeat dispersion (quantified by Poincaré plots) that is typically observed in SAN dysfunction (Fenske et al., 2013). Therefore, $\mathrm{HCN} 4$ apparently is required to protect the heart from severe bradycardia and $\mathrm{HCN} 2$ and $\mathrm{HCN} 1$ are required to prevent arrhythmias. 
Ivabradine is a specific $I_{f}$ blocker that reduces the heart rate in patients, specifically patients with inappropriate sinus tachycardia to eliminate arrhythmia (Cappato et al., 2012). However, a recent study in isolated rabbit pacemaker cells demonstrated that ivabradine, even at a concentration that specifically inhibits $I_{f}$, but does not directly suppress L-type current, SR $\mathrm{Ca}^{2+}$ cycling and other surface membrane ion channels, indirectly suppresses intracellular $\mathrm{Ca}^{2+}$ cycling (Yaniv et al., 2012, 2013b). The reduction in arrhythmic events is therefore likely due to drug effect on synchronization of functions within the coupled-clock system, and not simply to $I_{f}$ inhibition, per se (Yaniv and Lakatta, 2013).

\section{$\mathrm{Ca}_{v} 1.3$}

Voltage-gated $\mathrm{Ca}_{v} 1$ channels $\left(\mathrm{Ca}_{v} 1.2\right.$ and $\left.\mathrm{Ca}_{v} 1.3\right)$ mediate L-type $\mathrm{Ca}^{2+}$ channels that play distinct roles in mediating $\mathrm{Ca}^{2+}$ balance in the pacemaker cell. Both $\mathrm{Ca}_{v} 1.2$ and $\mathrm{Ca}_{v} 1.3$ channels are expressed in $\mathrm{SAN}$, and $\mathrm{Ca}_{v} 1.3$ expression in the atria and SAN cells is higher than in ventricular myocytes (Marger et al., 2011). $\mathrm{Ca}_{v} 1.3$ current is activated faster and at more negative voltages than $\mathrm{Ca}_{v} 1.2$ current and, therefore, in mice can contribute earlier during the diastolic depolarization (Christel et al., 2012). Bradycardia and arrhythmia are particularly prominent in $\mathrm{Ca}_{v} 1.3$ knockout mouse pacemaker cells (Mangoni et al., 2003). Loss of function of $\mathrm{Ca}_{v} 1.3$ both in mice and humans causes sick sinus syndrome (see above) and is characterized by severe bradycardia (Platzer et al., 2000; Baig et al., 2011). Moreover, patients with a mutation in the CACNA1D gene, which encodes the pore-forming $\alpha_{1}$ subunit of $\mathrm{Ca}_{v} 1.3$, experience pronounced bradycardia in 12-24-h ECG recordings, and their HRV timedomain indices are increased (Baig et al., 2011) (Figure 1D). Note that functional significance of $\mathrm{Ca}_{v} 1.3$ in large mammals has yet to be demonstrated.

\section{NCX1}

The $\mathrm{Na}^{+} / \mathrm{Ca}^{2+}$ exchanger has two important roles in pacemaker cells: it not only maintains the cell $\mathrm{Ca}^{2+}$ balance by matching $\mathrm{Ca}^{2+}$ efflux to $\mathrm{Ca}^{2+}$ influx through the L-type $\mathrm{Ca}^{2+}$ current, but also contributes to diastolic depolarization (Maltsev et al., 2014). Specific knockout of SAN $\mathrm{Na}^{+} / \mathrm{Ca}^{2+}$ exchanger mice induces bradycardia and increases BIV in the proportion of mycoytes that express arrhythmic AP BI compared to control mice (Herrmann et al., 2013) (Figure 1D). Interestingly, numerical model simulations predict that only a reduction in $\mathrm{Na}^{+} / \mathrm{Ca}^{2+}$ exchanger density to below a specific threshold is accompanied by arrhythmic AP BI (Maltsev et al., 2013).

\section{TRPM4}

TRPM4 is a monovalent nonselective cation channel permeable to $\mathrm{Na}^{+}, \mathrm{K}^{+}$, and $\mathrm{Li}^{+}$, but not to $\mathrm{Ca}^{2+}$ (Launay et al., 2002). Activation of TRPM4 channels that exist in murine pacemaker cells is achieved by both membrane depolarization and by a rise in intracellular $\mathrm{Ca}^{2+}$ (Hof et al., 2013). Although TRPM4 KO mice have heart rates similar to those of their controls, they exhibit a higher incidence of sinus pauses (Hof et al., 2013).

\section{RYANODINE CHANNELS}

The stochasticity of spontaneous RyR activation determines the diastolic $\mathrm{LCR} \mathrm{Ca}^{2+}$ signal and therefore the degree of synchronization of intracellular function of the coupled-clock system. A mutation in RyR, exon-3, in patients with catecholaminergic polymorphic ventricular tachycardia, is associated with arrhythmias (Bhuiyan et al., 2007) (Figure 1D). Isolated pacemaker cells from mice that express this mutation have a prolonged average AP BI with pauses between AP BIs together with an impaired chronotropic response to $\beta$ adrenergic stimulation (Neco et al., 2012). Similarly, in inducible, heart tissuespecific RyR2 knockout mice, both in vivo ECG telemetry and in vitro isolated perfused heart, demonstrated bradycardic $\mathrm{BI}$ and arrhythmia (Bround et al., 2012).

\section{Shox2 AND OTHER TRANSCRIPTION FACTORS}

The Shox 2 transcriptional factor has been identified as a key regulator in pacemaker formation and differentiation (Liu et al., 2011). Shox 2 gene $\mathrm{KO}$ mice have a significantly reduced heart beat rate and increased number of arrhythmic events (Liu et al., 2011) (Figure 1D). Moreover, deficient Shox2 transcription factor during development may cause abnormal of mouse SAN development associated with severe arrhythmias (Hoffmann et al., 2013). Therefore, the Shox 2 gene also appears to be critical for normal pacemaking function. Other transcription factors than Shox2 are involved in pacemaker function. In this regard, expression of Tbx18 in guinea pig has been shown as an essential gene whose expression can convert quiescent cardiomyocytes to pacemaker cells (Kapoor et al., 2013), therefore, increasing the pacemakerinduced spontaneous beating rate of the cells and decreasing their BIV. Interestingly, Tbx18 transduction to the guinea pig embryonic cell lineage inhibits $\mathrm{Cx} 43$ expression, leading to significant electrical uncoupling (Kapoor et al., 2011).

\section{ANKYRIN-B}

Ankyrins are adaptor proteins that are required for targeting channels and transporters in pacemaker cells to the membranes in which they function. Human patients with ankyrin-Bdeficiency have highly penetrant sinus node dysfunction coupled with increased susceptibility to spontaneous and inducible atrial fibrillation (Le Scouarnec et al., 2008). Interestingly, ankyrin-B -deficient mice also have reduced expression of $\mathrm{Na}^{+} / \mathrm{Ca}^{2+}$ exchanger and $\mathrm{Na}^{+} / \mathrm{K}^{+}$ATPase (Le Scouarnec et al., 2008). Finally, cells isolated from ankyrin-B-deficient mice have increased BIV (Cunha et al., 2011) (Figure 1D). Thus, down regulation of ankyrin-B induces abnormal membrane organization that is implicated in a reduced efficiency of pacemaker clock coupling that causes abnormal electrical activity within SAN.

\section{CELL-TO-CELL UNCOUPLING MECHANISMS}

As described above, the BIs of pacemaker cells residing in the SAN become entrained by electrotonic and mechanical cell-tocell interactions within the tissue (Jalife, 1984; Watanabe et al., 1995). Numerical model simulations predict that cardiac arrhythmias can occur when normal coupling between pacemaker cells in SAN tissue is perturbed (Ostborn et al., 2001). Cardiac diseases, and specifically sick sinus syndrome, are associated with reduction in cell-cell junctional proteins (Dobrzynski et al., 2007). ECG of mice with a cardiac conduction-specific knockout of desmoplakin, a protein that affects mechanical cell-to-cell interaction in 
the cardiac conduction system, exhibits sinus arrhythmias characterized by a strikingly increased number of sinus pauses compared to wild-type mice (Sheikh et al., 2013).

\section{PASSIVE MECHANISMS}

Although connexin43 is absent in the center of the pacemaker tissue, it is expressed in the peripheral area. A reduction in connexin 43 in aged guinea pig SAN is associated with a reduction in heart rate and an increase in arrhythmogenic events (Jones et al., 2004). Moreover, pacemaker tissue contains functional gap junctions and connecting cardiac fibroblasts (Camelliti et al., 2004). Because an increase in fibroblasts expression can slow the generation of pacemaker excitability, it may be involved in bradycardia and sick sinus syndrome (for review see Kohl et al., 2005). A detailed review of the role of passive pacemaker tissue properties on its electrical conductance is present in this issue (Unudurthi et al., 2014).

\section{REDUCED EFFICIENCY OF SYNCHRONIZATION OF ACTIVITY ACROSS POPULATIONS OF CELLS AND ARRHYTHMIA}

High-resolution optical mapping of SAN tissue has helped to resolve how reduced synchronization of activity across populations of cells within the SAN can induce arrhythmia. In this regard, different intrinsic mechanisms can be involved in tachybrady heart-rate alteration and exit block that leads to long sinus pauses and increases susceptibility to cardiac arrhythmias: (i) an increase in adenosine level in human SAN tissue, an endogenous metabolite of the heart, through adenosine A1 receptor upregulating, can lead to SAN dysfunction (Lou et al., 2013, 2014); (ii) an increase in B-type and C-type natriuretic peptides increase the mice SAN conduction velocity and shift the initial exit site (Azer et al., 2014). (iii) Mutation in $\mathrm{Ca}^{2+}$-binding protein calsequestrin 2 is associated with different cardiac diseases. In calsequestrin knockout mice the SAN exhibits bradycardia, conduction abnormalities and increase beat-to-beat variability (Glukhov et al., 2013). (iv) Ganglion nerve plexi can stimulate the intrinsic cardiac nervous system. In mice pulmonary vein ganglia stimulation shifts the origin of SAN discharges and decreases the heart rate (Zarzoso et al., 2013). (v) Impaired SR function in canine failing hearts results in an impaired shift in the location of the pacemaker site in response to $\beta$-AR stimulation (Shinohara et al., 2010).

\section{SUMMARY}

Changes in heart rate and rhythm are harbingers of the appearance of arrhythmogenic events. Reduction in the degree of synchronization of any intrinsic clock functions of pacemaker cells or in the synchronization among pacemaker cells residing in the SAN can be associated with arrhythmia occurrence. The extent to which restoring normal synchronization of intrinsic clock periods within pacemaker cells and among pacemaker cells can prevent arrhythmogenic events awaits further elucidation. In our opinion, future work requires a focus on the connection between dysfunction of inherent intrinsic mechanisms associated with different cardiac diseases and cardiac arrhythmias. This connection can be explored in genetically manipulated mouse models, in animals like rabbit, dog and sheep with heart failure or atrial fibrillation, and in human-derived cardiomyocytes or human SAN. This knowledge will contribute greatly to our understanding of cardiac impulse initiation in health and in cardiac disease.

\section{ACKNOWLEDGMENTS}

This research was partially supported by the Intramural Research Program of the NIH, National Institute on Aging, by Technion VPR Fund -Krbling Biomedical Engineering Research Fund (YY) and by NSFC-ISF joint research program, No. 398/14 (YY).

\section{REFERENCES}

Akyurek, O., Diker, E., Guldal, M., and Oral, D. (2003). Predictive value of heart rate variability for the recurrence of chronic atrial fibrillation after electrical cardioversion. Clin. Cardiol. 26, 196-200. doi: 10.1002/clc.4960260411

Anumonwo, J. M., Delmar, M., Vinet, A., Michaels, D. C., and Jalife, J. (1991). Phase resetting and entrainment of pacemaker activity in single sinus nodal cells. Circ. Res. 68, 1138-1153. doi: 10.1161/01.RES.68.4.1138

Azer, J., Hua, R., Krishnaswamy, P. S., and Rose, R. A. (2014). Effects of natriuretic peptides on electrical conduction in the sinoatrial node and atrial myocardium of the heart. J. Physiol. 592, 1025-1045. doi: 10.1113/jphysiol.2013.265405

Baig, S. M., Koschak, A., Lieb, A., Gebhart, M., Dafinger, C., Nurnberg, G., et al. (2011). Loss of $\mathrm{Ca}(\mathrm{v}) 1.3$ (CACNA1D) function in a human channelopathy with bradycardia and congenital deafness. Nat. Neurosci. 14, 77-84. doi: 10.1038/nn.2694

Battipaglia, I., Scalone, G., Macchione, A., Pinnacchio, G., Laurito, M., Milo, M., et al. (2012). Association of heart rate variability with arrhythmic events in patients with arrhythmogenic right ventricular cardiomyopathy/dysplasia. Circ. J. 76, 618-623. doi: 10.1253/circj.CJ-11-1052

Bergfeldt, L., and Haga, Y. (2003). Power spectral and Poincare plot characteristics in sinus node dysfunction. J. Appl. Physiol. (1985). 94, 2217-2224. doi: 10.1152/japplphysiol.01037.2002

Bhuiyan, Z. A., Van Den Berg, M. P., Van Tintelen, J. P., Bink-Boelkens, M. T., Wiesfeld, A. C., Alders, M., et al. (2007). Expanding spectrum of human RYR2related disease: new electrocardiographic, structural, and genetic features. Circulation 116, 1569-1576. doi: 10.1161/CIRCULATIONAHA.107.711606

Birchfield, R. I., Menefee, E. E., and Bryant, G. D. (1957). Disease of the sinoatrial node associated with bradycardia, asystole, syncope, and paroxysmal atrial fibrillation. Circulation 16, 20-26. doi: 10.1161/01.CIR.16.1.20

Boyett, M. R., Honjo, H., and Kodama, I. (2000). The sinoatrial node, a heterogeneous pacemaker structure. Cardiovasc. Res. 47, 658-687. doi: 10.1016/S00086363(00)00135-8

Bround, M. J., Asghari, P., Wambolt, R. B., Bohunek, L., Smits, C., Philit, M., et al. (2012). Cardiac ryanodine receptors control heart rate and rhythmicity in adult mice. Cardiovasc. Res. 96, 372-380. doi: 10.1093/cvr/cvs260

Camelliti, P., Green, C. R., Legrice, I., and Kohl, P. (2004). Fibroblast network in rabbit sinoatrial node: structural and functional identification of homogeneous and heterogeneous cell coupling. Circ. Res. 94, 828-835. doi: 10.1161/01.RES.0000122382.19400.14

Cappato, R., Castelvecchio, S., Ricci, C., Bianco, E., Vitali-Serdoz, L., GnecchiRuscone, T., et al. (2012). Clinical efficacy of ivabradine in patients with inappropriate sinus tachycardia: a prospective, randomized, placebo-controlled, double-blind, crossover evaluation. J. Am. Coll. Cardiol. 60, 1323-1329. doi: 10.1016/j.jacc.2012.06.031

Childers, R. W., Arnsdorf, M. F., De La Fuente, D. J., Gambetta, M., and Svenson, R. (1973). Sinus nodal echoes. Clinical case report and canine studies. Am. J. Cardiol. 31, 220-231. doi: 10.1016/0002-9149(73)91035-7

Christel, C. J., Cardona, N., Mesirca, P., Herrmann, S., Hofmann, F., Striessnig, J., et al. (2012). Distinct localization and modulation of Cav1.2 and Cav1.3 Ltype $\mathrm{Ca}^{2+}$ channels in mouse sinoatrial node. J. Physiol. 590, 6327-6342. doi: 10.1113/jphysiol.2012.239954

Cossu, S. F., and Steinberg, J. S. (1998). Supraventricular tachyarrhythmias involving the sinus node: clinical and electrophysiologic characteristics. Prog. Cardiovasc. Dis. 41, 51-63. doi: 10.1016/S0033-0620(98)80022-4

Costa, M. D., Peng, C. K., and Goldberger, A. L. (2008). Multiscale analysis of heart rate dynamics: entropy and time irreversibility measures. Cardiovasc. Eng. 8, 88-93. doi: 10.1007/s10558-007-9049-1

Cunha, S. R., Hund, T. J., Hashemi, S., Voigt, N., Li, N., Wright, P., et al. (2011). Defects in ankyrin-based membrane protein targeting 
pathways underlie atrial fibrillation. Circulation 124, 1212-1222. doi: 10.1161/CIRCULATIONAHA.111.023986

De Jong, A. M., Maass, A. H., Oberdorf-Maass, S. U., De Boer, R. A., Van Gilst, W. H., and Van Gelder, I. C. (2013). Cyclical stretch induces structural changes in atrial myocytes. J. Cell. Mol. Med. 17, 743-753. doi: 10.1111/jcmm.12064

Difrancesco, D. (1993). Pacemaker mechanisms in cardiac tissue. Annu. Rev. Physiol. 55, 455-472. doi: 10.1146/annurev.ph.55.030193.002323

Dobrzynski, H., Boyett, M. R., and Anderson, R. H. (2007). New insights into pacemaker activity: promoting understanding of sick sinus syndrome. Circulation 115, 1921-1932. doi: 10.1161/CIRCULATIONAHA.106.616011

Duhme, N., Schweizer, P. A., Thomas, D., Becker, R., Schroter, J., Barends, T. R., et al. (2013). Altered HCN4 channel C-linker interaction is associated with familial tachycardia-bradycardia syndrome and atrial fibrillation. Eur. Heart J. 34, 2768-2775. doi: 10.1093/eurheartj/ehs391

Fenske, S., Krause, S. C., Hassan, S. I., Becirovic, E., Auer, F., Bernard, R., et al. (2013). Sick sinus syndrome in HCN1-deficient mice. Circulation 128, 2585-2594. doi: 10.1161/CIRCULATIONAHA.113.003712

Gang, U. J., Jons, C., Jorgensen, R. M., Abildstrom, S. Z., Messier, M. D., Haarbo, J., et al. (2011). Risk markers of late high-degree atrioventricular block in patients with left ventricular dysfunction after an acute myocardial infarction: a CARISMA substudy. Europace 13, 1471-1477. doi: 10.1093/europace/ eur165

Glukhov, A. V., Kalyanasundaram, A., Lou, Q., Hage, L. T., Hansen, B. J., Belevych, A. E., et al. (2013). Calsequestrin 2 deletion causes sinoatrial node dysfunction and atrial arrhythmias associated with altered sarcoplasmic reticulum calcium cycling and degenerative fibrosis within the mouse atrial pacemaker complex. Eur. Heart J. doi: 10.1093/eurheartj/eht452. [Epub ahead of print].

Gomes, J. A., Mehta, D., and Langan, M. N. (1995). Sinus node reentrant tachycardia. Pacing Clin. Electrophysiol. 18, 1045-1057. doi: 10.1111/j.15408159.1995.tb04747.x

Han, J., Malozzi, A. M., Moe, G. K. (1968). Sino-atrial reciprocation in the isolated rabbit heart. Circ. Res. 22, 355-362.

Herrmann, S., Lipp, P., Wiesen, K., Stieber, J., Nguyen, H., Kaiser, E., et al. (2013). The cardiac sodium-calcium exchanger NCX1 is a key player in the initiation and maintenance of a stable heart rhythm. Cardiovasc. Res. 99, 780-788. doi: $10.1093 / \mathrm{cvr} / \mathrm{cvt} 154$

Herrmann, S., Stieber, J., Stockl, G., Hofmann, F., and Ludwig, A. (2007). HCN4 provides a 'depolarization reserve' and is not required for heart rate acceleration in mice. EMBO J. 26, 4423-4432. doi: 10.1038/sj.emboj.7601868

Hof, T., Simard, C., Rouet, R., Salle, L., and Guinamard, R. (2013). Implication of the TRPM4 nonselective cation channel in mammalian sinus rhythm. Heart Rhythm 10, 1683-1689. doi: 10.1016/j.hrthm.2013.08.014

Hoffmann, S., Berger, I. M., Glaser, A., Bacon, C., Li, L., Gretz, N., et al. (2013). Isletl is a direct transcriptional target of the homeodomain transcription factor Shox 2 and rescues the Shox2-mediated bradycardia. Basic Res. Cardiol. 108, 339. doi: 10.1007/s00395-013-0339-z

Huikuri, H. V., Raatikainen, M. J., Moerch-Joergensen, R., Hartikainen, J., Virtanen, V., Boland, J., et al. (2009). Prediction of fatal or near-fatal cardiac arrhythmia events in patients with depressed left ventricular function after an acute myocardial infarction. Eur. Heart J. 30, 689-698. doi: 10.1093/eurheartj/ehn537

Huikuri, H. V., Valkama, J. O., Airaksinen, K. E., Seppanen, T., Kessler, K. M., Takkunen, J. T., et al. (1993). Frequency domain measures of heart rate variability before the onset of nonsustained and sustained ventricular tachycardia in patients with coronary artery disease. Circulation 87, 1220-1228. doi: 10.1161/01.CIR.87.4.1220

Jalife, J. (1984). Mutual entrainment and electrical coupling as mechanisms for synchronous firing of rabbit sino-atrial pace-maker cells. J. Physiol. 356, 221-243. doi: 10.1113/jphysiol.1984.sp015461

Jones, S. A., Lancaster, M. K., and Boyett, M. R. (2004). Ageing-related changes of connexins and conduction within the sinoatrial node. J. Physiol. 560, 429-437. doi: 10.1113/jphysiol.2004.072108

Kapoor, N., Galang, G., Marban, E., and Cho, H. C. (2011). Transcriptional suppression of connexin43 by TBX18 undermines cell-cell electrical coupling in postnatal cardiomyocytes. J. Biol. Chem. 286, 14073-14079. doi: 10.1074/jbc.M110.185298

Kapoor, N., Liang, W., Marban, E., and Cho, H. C. (2013). Direct conversion of quiescent cardiomyocytes to pacemaker cells by expression of Tbx18. Nat. Biotechnol. 31, 54-62. doi: 10.1038/nbt.2465
Kocovic, D. Z., Harada, T., Shea, J. B., Soroff, D., and Friedman, P. L. (1993). Alterations of heart rate and of heart rate variability after radiofrequency catheter ablation of supraventricular tachycardia. Delineation of parasympathetic pathways in the human heart. Circulation 88, 1671-1681. doi: 10.1161/01.CIR.88.4.1671

Kohl, P., Camelliti, P., Burton, F. L., and Smith, G. L. (2005). Electrical coupling of fibroblasts and myocytes: relevance for cardiac propagation. J. Electrocardiol. 38, 45-50. doi: 10.1016/j.jelectrocard.2005.06.096

Launay, P., Fleig, A., Perraud, A. L., Scharenberg, A. M., Penner, R., and Kinet, J. P. (2002). TRPM4 is a $\mathrm{Ca}^{2+}$-activated nonselective cation channel mediating cell membrane depolarization. Cell 109, 397-407. doi: 10.1016/S00928674(02)00719-5

Le Scouarnec, S., Bhasin, N., Vieyres, C., Hund, T. J., Cunha, S. R., Koval, O., et al. (2008). Dysfunction in ankyrin-B-dependent ion channel and transporter targeting causes human sinus node disease. Proc. Natl. Acad. Sci. U.S.A. 105, 15617-15622. doi: 10.1073/pnas.0805500105

Liu, H., Chen, C. H., Espinoza-Lewis, R. A., Jiao, Z., Sheu, I., Hu, X., et al. (2011). Functional redundancy between human SHOX and mouse Shox 2 genes in the regulation of sinoatrial node formation and pacemaking function. J. Biol. Chem. 286, 17029-17038. doi: 10.1074/jbc.M111.234252

Lou, Q., Glukhov, A. V., Hansen, B., Hage, L., Vargas-Pinto, P., Billman, G. E., et al. (2013). Tachy-brady arrhythmias: the critical role of adenosine-induced sinoatrial conduction block in post-tachycardia pauses. Heart Rhythm 10, 110-118. doi: 10.1016/j.hrthm.2012.09.012

Lou, Q., Hansen, B. J., Fedorenko, O., Csepe, T. A., Kalyanasundaram, A., Li, N., et al. (2014). Upregulation of adenosine Al receptors facilitates sinoatrial node dysfunction in chronic canine heart failure by exacerbating nodal conduction abnormalities revealed by novel dual-sided intramural optical mapping. Circulation 130, 315-324. doi: 10.1161/CIRCULATIONAHA.113.007086

Ludwig, A., Zong, X., Jeglitsch, M., Hofmann, F., and Biel, M. (1998). A family of hyperpolarization-activated mammalian cation channels. Nature 393, 587-591. doi: $10.1038 / 31255$

Makikallio, T. H., Koistinen, J., Jordaens, L., Tulppo, M. P., Wood, N., Golosarsky, B., et al. (1999). Heart rate dynamics before spontaneous onset of ventricular fibrillation in patients with healed myocardial infarcts. Am. J. Cardiol. 83, 880-884. doi: 10.1016/S0002-9149(98)01068-6

Maltsev, A. V., Yaniv, Y., Stern, M. D., Lakatta, E. G., and Maltsev, V. A. (2013). RyR-NCX-SERCA local cross-talk ensures pacemaker cell function at rest and during the fight-or-flight reflex. Circ. Res. 113, e94-e100. doi: 10.1161/CIRCRESAHA.113.302465

Maltsev, V. A., Yaniv, Y., Maltsev, A. V., Stern, M. D., and Lakatta, E. G. (2014). Modern perspectives on numerical modeling of cardiac pacemaker cell. J. Pharmacol. Sci. 125, 6-38. doi: 10.1254/jphs.13R04CR

Mangoni, M. E., Couette, B., Bourinet, E., Platzer, J., Reimer, D., Striessnig, J., et al. (2003). Functional role of L-type Cav1.3 $\mathrm{Ca}^{2+}$ channels in cardiac pacemaker activity. Proc. Natl. Acad. Sci. U.S.A. 100, 5543-5548. doi: 10.1073/pnas.0935295100

Marger, L., Mesirca, P., Alig, J., Torrente, A., Dubel, S., Engeland, B., et al. (2011). Functional roles of $\mathrm{Ca}(\mathrm{v}) 1.3, \mathrm{Ca}(\mathrm{v}) 3.1$ and $\mathrm{HCN}$ channels in automaticity of mouse atrioventricular cells: insights into the atrioventricular pacemaker mechanism. Channels (Austin) 5, 251-261. doi: 10.4161/chan.5.3.15266

Monfredi, O., Lyashkov, A. E., Johnsen, A. B., Inada, S., Schneider, H., Wang, R., et al. (2014). Biophysical characterization of the underappreciated and important relationship between heart rate variability and heart rate. Hypertension 64, 1334-1343. doi: 10.1161/HYPERTENSIONAHA.114.03782

Monfredi, O., Maltseva, L. A., Spurgeon, H. A., Boyett, M. R., Lakatta, E. G., and Maltsev, V. A. (2013). Beat-to-beat variation in periodicity of local calcium releases contributes to intrinsic variations of spontaneous cycle length in isolated single sinoatrial node cells. PLoS ONE 8:e67247. doi: 10.1371/journal.pone.0067247

Neco, P., Torrente, A. G., Mesirca, P., Zorio, E., Liu, N., Priori, S. G., et al. (2012). Paradoxical effect of increased diastolic $\mathrm{Ca}^{(2+)}$ release and decreased sinoatrial node activity in a mouse model of catecholaminergic polymorphic ventricular tachycardia. Circulation 126, 392-401. doi: 10.1161/CIRCULATIONAHA.111.075382

Osaka, M., Watanabe, E., Murata, H., Fuwamoto, Y., Nanba, S., Sakai, K., et al. (2010). V-shaped trough in autonomic activity is a possible precursor of life-threatening cardiac events. Circ. J. 74, 1906-1915. doi: 10.1253/circj.CJ09-0935 
Ostborn, P., Wohlfart, B., Ohlén, G. (2001). Arrhythmia as a result of poor intercellular coupling in the sinus node: a simulation study. J. Theor. Biol. 211, 201-217. doi: 10.1006/jtbi.2001.2339

Papaioannou, V. E., Verkerk, A. O., Amin, A. S., and De Bakker, J. M. (2013). Intracardiac origin of heart rate variability, pacemaker funny current and their possible association with critical illness. Curr. Cardiol. Rev. 9, 82-96. doi: $10.2174 / 157340313805076359$

Perkiomaki, J., Ukkola, O., Kiviniemi, A., Tulppo, M., Ylitalo, A., Kesaniemi, Y. A., et al. (2014). Heart rate variability findings as a predictor of atrial fibrillation in middle-aged population. J. Cardiovasc. Electrophysiol. 25, 719-724. doi: 10.1111 /jce. 12402

Platzer, J., Engel, J., Schrott-Fischer, A., Stephan, K., Bova, S., Chen, H., et al. (2000). Congenital deafness and sinoatrial node dysfunction in mice lacking class D L-type $\mathrm{Ca}^{2+}$ channels. Cell 102, 89-97. doi: 10.1016/S0092-8674(00)00013-1

Postolache, G., Oliveira, M., Rocha, I., Girao, P. S., and Postolache, O. (2011). New insight into arrhythmia onset using HRV and BPV analysis. Conf. Proc. IEEE Eng. Med. Biol. Soc. 2011, 2691-2694. doi: 10.1109/IEMBS.2011.6090739

Rocchetti, M., Malfatto, G., Lombardi, F., and Zaza, A. (2000). Role of the input/output relation of sinoatrial myocytes in cholinergic modulation of heart rate variability. J. Cardiovasc. Electrophysiol. 11, 522-530. doi: 10.1111/j.15408167.2000.tb00005.x

Rozen, G., Kobo, R., Beinart, R., Feldman, S., Sapunar, M., Luria, D., et al. (2013). Multipole analysis of heart rate variability as a predictor of imminent ventricular arrhythmias in ICD patients. Pacing Clin. Electrophysiol. 36, 1342-1347. doi: $10.1111 /$ pace. 12180

Schweizer, P. A., Duhme, N., Thomas, D., Becker, R., Zehelein, J., Draguhn, A., et al. (2010). cAMP sensitivity of HCN pacemaker channels determines basal heart rate but is not critical for autonomic rate control. Circ. Arrhythm. Electrophysiol. 3, 542-552. doi: 10.1161/CIRCEP.110.949768

Seaborn, G. E., Todd, K., Michael, K. A., Baranchuk, A., Abdollah, H., Simpson, C. S., et al. (2014). Heart rate variability and procedural outcome in catheter ablation for atrial fibrillation. Ann. Noninvasive Electrocardiol. 19, 23-33. doi: 10.1111/anec. 12098

Sheikh, F., Mezzano, V., Wright, A., Zanella, F., Lyon, R. S., Gu, Y., et al. (2013). A novel role for mechanical cell-cell junction proteins in sinus node function. J. Mol. Cell. Cardiol. 65.

Shinohara, T., Park, H. W., Han, S., Shen, M. J., Maruyama, M., Kim, D., et al. (2010). $\mathrm{Ca}^{2+}$ clock malfunction in a canine model of pacing-induced heart failure. Am. J. Physiol. Heart Circ. Physiol. 299, H1805-H1811. doi: 10.1152/ajpheart.00723.2010

Slovut, D. P., Wenstrom, J. C., Moeckel, R. B., Wilson, R. F., Osborn, J. W., and Abrams, J. H. (1998). Respiratory sinus dysrhythmia persists in transplanted human hearts following autonomic blockade. Clin. Exp. Pharmacol. Physiol. 25, 322-330. doi: 10.1111/j.1440-1681.1998.tb02358.x

Stieber, J., Hofmann, F., and Ludwig, A. (2004). Pacemaker channels and sinus node arrhythmia. Trends Cardiovasc. Med. 14, 23-28. doi: 10.1016/j.tcm.2003.09.006

Unudurthi, S. D., Wolf, R. M., and Hund, T. J. (2014). Role of sinoatrial node architecture in maintaining a balanced source-sink relationship and synchronous cardiac pacemaking. Front. Physiol. 5:446. doi: 10.3389/fphys.2014.00446

Verheijck, E. E., Wilders, R., Joyner, R. W., Golod, D. A., Kumar, R., Jongsma, H. J., et al. (1998). Pacemaker synchronization of electrically coupled rabbit sinoatrial node cells. J. Gen. Physiol. 111, 95-112. doi: 10.1085/jgp.111.1.95

Vybiral, T., Glaeser, D. H., Goldberger, A. L., Rigney, D. R., Hess, K. R., Mietus, J., et al. (1993). Conventional heart rate variability analysis of ambulatory electrocardiographic recordings fails to predict imminent ventricular fibrillation. J. Am. Coll. Cardiol. 22, 557-565. doi: 10.1016/0735-1097(93)90064-8

Wang, K., Chang, D., Chu, Z., Yang, Y., Gao, L., Zhang, S., et al. (2013). Denervation as a common mechanism underlying different pulmonary vein isolation strategies for paroxysmal atrial fibrillation: evidenced by heart rate variability after ablation. Sci. World J. 2013:569564. doi: 10.1155/2013/569564

Watanabe, E. I., Honjo, H., Anno, T., Boyett, M. R., Kodama, I., and Toyama, J. (1995). Modulation of pacemaker activity of sinoatrial node cells by electrical load imposed by an atrial cell model. Am. J. Physiol. 269, H1735-H1742.

Yaniv, Y., Ahmet, I., Liu, J., Lyashkov, A. E., Guiriba, T. R., Okamoto, Y., et al. (2014a). Synchronization of sinoatrial node pacemaker cell clocks and its autonomic modulation impart complexity to heart beating intervals. Heart Rhythm 11, 1210-1219. doi: 10.1016/j.hrthm.2014.03.049
Yaniv, Y., and Lakatta, E. G. (2013). Pacemaker gene mutations, bradycardia, arrhythmias and the coupled clock theory. J. Cardiovasc. Electrophysiol. 24, E28-E29. doi: 10.1111/jce.12236

Yaniv, Y., Lyashkov, A. E., and Lakatta, E. G. (2013a). The fractal-like complexity of heart rate variability beyond neurotransmitters and autonomic receptors: signaling intrinsic to sinoatrial node pacemaker cells. Cardiovasc. Pharmacol. 2:111. doi: 10.4172/2329-6607.1000111

Yaniv, Y., Lyashkov, A. E., Sirenko, S., Okamoto, Y., Guiriba, T. R., Ziman, B. D., et al. (2014b). Stochasticity intrinsic to coupled-clock mechanisms underlies beat-to-beat variability of spontaneous action potential firing in sinoatrial node pacemaker cells. J. Mol. Cell. Cardiol. 77, 1-10. doi: 10.1016/j.yjmcc.2014. 09.008

Yaniv, Y., Maltsev, V. A., Escobar, A. L., Spurgeon, H. A., Ziman, B. D., Stern, M. D., et al. (2011). Beat-to-beat $\mathrm{Ca}^{(2+)}$-dependent regulation of sinoatrial nodal pacemaker cell rate and rhythm. J. Mol. Cell. Cardiol. 51, 902-905. doi: 10.1016/j.yjmcc.2011.08.029

Yaniv, Y., Maltsev, V. A., Ziman, B. D., Spurgeon, H. A., and Lakatta, E. G. (2012). The "Funny" current inhibition by ivabradine at membrane potentials encompassing spontaneous depolarization in pacemaker cells. Molecules 17, 8241-8254. doi: 10.3390/molecules17078241

Yaniv, Y., Sirenko, S., Ziman, B. D., Spurgeon, H. A., Maltsev, V. A., and Lakatta, E. G. (2013b). New evidence for coupled clock regulation of the normal automaticity of sinoatrial nodal pacemaker cells: bradycardic effects of ivabradine are linked to suppression of intracellular $\mathrm{Ca}^{(2)(+)}$ cycling. J. Mol. Cell. Cardiol. 62, 80-89. doi: 10.1016/j.yjmcc.2013.04.026

Yaniv, Y., Spurgeon, H. A., Ziman, B. D., and Lakatta, E. G. (2013c). $\mathrm{Ca}^{(2)+} /$ calmodulin-dependent protein kinase II (CaMKII) activity and sinoatrial nodal pacemaker cell energetics. PLoS ONE 8:e57079. doi: 10.1371/journal.pone.0057079

Yaniv, Y., Stern, M. D., Lakatta, E. G., and Maltsev, V. A. (2013d). Mechanisms of beat-to-beat regulation of cardiac pacemaker cell function by $\mathrm{Ca}^{(2)(+)}$ cycling dynamics. Biophys. J. 105, 1551-1561. doi: 10.1016/j.bpj.2013.08.024

Yeh, Y. H., Burstein, B., Qi, X. Y., Sakabe, M., Chartier, D., Comtois, P., et al. (2009). Funny current downregulation and sinus node dysfunction associated with atrial tachyarrhythmia: a molecular basis for tachycardia-bradycardia syndrome. Circulation 119, 1576-1585. doi: 10.1161/CIRCULATIONAHA.108.789677

Younes, A., Lyashkov, A. E., Graham, D., Sheydina, A., Volkova, M. V., Mitsak, M., et al. (2008). $\mathrm{Ca}^{(2+)}$-stimulated basal adenylyl cyclase activity localization in membrane lipid microdomains of cardiac sinoatrial nodal pacemaker cells. J. Biol. Chem. 283, 14461-14468. doi: 10.1074/jbc.M707 540200

Zarzoso, M., Rysevaite, K., Milstein, M. L., Calvo, C. J., Kean, A. C., Atienza, F., et al. (2013). Nerves projecting from the intrinsic cardiac ganglia of the pulmonary veins modulate sinoatrial node pacemaker function. Cardiovasc. Res. 99, 566-575. doi: 10.1093/cvr/cvt081

Zaza, A., and Lombardi, F. (2001). Autonomic indexes based on the analysis of heart rate variability: a view from the sinus node. Cardiovasc. Res. 50, 434-442. doi: 10.1016/S0008-6363(01)00240-1

Conflict of Interest Statement: The authors declare that the research was conducted in the absence of any commercial or financial relationships that could be construed as a potential conflict of interest.

Received: 15 November 2014; accepted: 03 February 2015; published online: 23 February 2015.

Citation: Yaniv Y, Tsutsui K and Lakatta EG (2015) Potential effects of intrinsic heart pacemaker cell mechanisms on dysrhythmic cardiac action potential firing. Front. Physiol. 6:47. doi: 10.3389/fphys.2015.00047

This article was submitted to Cardiac Electrophysiology, a section of the journal Frontiers in Physiology.

Copyright (c) 2015 Yaniv, Tsutsui and Lakatta. This is an open-access article distributed under the terms of the Creative Commons Attribution License (CC BY). The use, distribution or reproduction in other forums is permitted, provided the original author(s) or licensor are credited and that the original publication in this journal is cited, in accordance with accepted academic practice. No use, distribution or reproduction is permitted which does not comply with these terms. 